\title{
Exhaust emissions from vehicles in real traffic conditions in the Poznan agglomeration
}

\author{
J. Merkisz, J. Pielecha, P. Lijewski, A. Merkisz-Guranowska \\ \& M. Nowak \\ Poznan University of Technology, Poland
}

\begin{abstract}
The paper presents an attempt to evaluate the exhaust emissions generated by transport in the Poznan agglomeration. The basis for the modeling of the exhaust emissions was the on-going characteristics of the individual groups of vehicles and a forecasted structure change of these groups for the years 2012-2030. The determination of average on-road emissions as a function of daily distance covered by individual vehicle groups was the basis for the determination of the change in the annual pollution. The assumed values of the exhaust emission concentrations from passenger vehicles were based on the performed tests under actual traffic conditions while for the other categories the authors adopted the test results of earlier works of the research team with the Chair of Combustion Engines at Poznan University of Technology. In the paper the authors assumed an increase in the share of vehicles meeting the latest applicable emission standards as well as changes in the distance covered by the vehicles. The result of the analysis will be accumulated annual exhaust emissions for a given vehicle category operating in the Poznan agglomeration.
\end{abstract}

Keywords: exhaust emission, real road conditions, modeling.

\section{Introduction}

The commonly applied models of total exhaust emissions from transport to the environment have a complex mathematical structure, and their characteristics and parameters depend on a great number of quantities. The characteristics of the models of total exhaust emissions are relations approximating the empirical research in the analyzed physical quantities. For these reasons the most difficult task is to provide reliable data for the research of the emission model, 
particularly since the official statistics related to transport are characterized by a high level of generalization (e.g. number of vehicles). Inaccuracies in determining of the input quantities of a model contribute to a multiplication of the error when determining the result values [3].

\section{Research methodology}

The tests were performed for the Poznan agglomeration; the basis for the modeling of the emission of the exhaust components was the on-going characteristics of individual group of vehicles and their forecasted change for the years 2012-2030 (Fig. 1). A change in the share of the emission categories in the total vehicle group was assumed: a gradual reduction of the share of vehicles compliant with early standards and an increase in the share of vehicles compliant with the latest applicable standards (including hybrid and electric vehicles).


Figure 1: Change in the vehicle structure in the Poznan agglomeration in the years 2012-2030. 
The adoption of the characteristics of average daily distance covered by individual categories of vehicles (Fig. 2) was the basis for the determination of changes in the daily pollution. They have been estimated based on the data included in the 'City of Poznan Integrated Transport Policy' in the description to the Copert 4 project [12] and presentation [11]. The values of the on-road gaseous emissions for the individual categories of vehicles we can assume according to a given vehicle emission standard (assuming that the vehicle generates the emissions within the limits set forth in the standard applicable for this vehicle) $[9,10]$ or based on the tests carried out under actual traffic conditions for a given agglomeration [2].
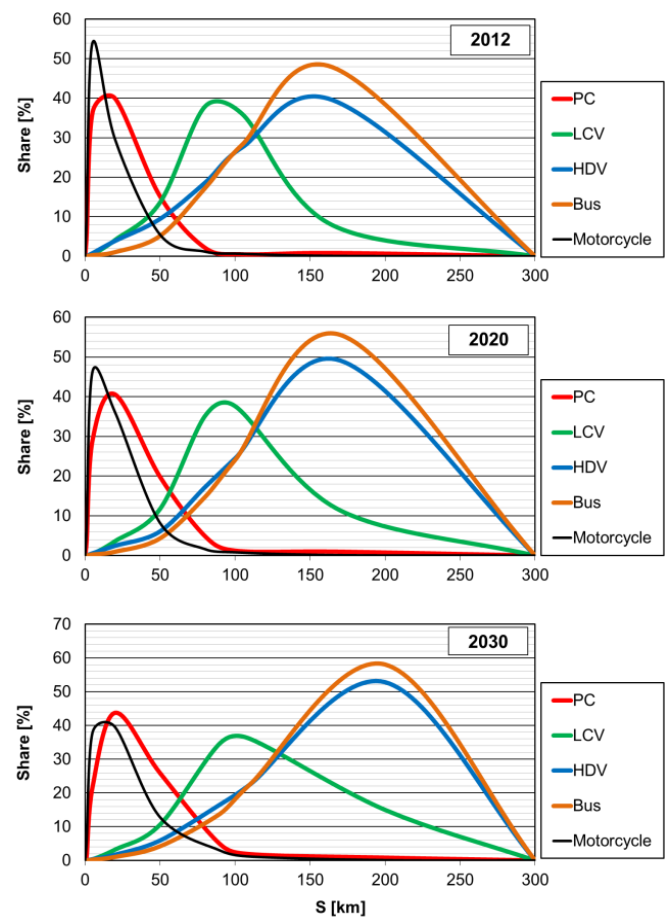

Figure 2: The assumed characteristics of daily distance covered by various vehicles.

\section{Exhaust emissions tests from vehicles operating under actual traffic conditions in the city of Poznan}

The values of the exhaust emission rate from passenger vehicles were determined based on the performed tests under actual traffic conditions (example results have been presented for Euro 4 and Euro 5 compliant diesel passenger vehicles) using a portable exhaust emissions measurement equipment (Semtech DS, an exhaust emissions analyzer by Sensors Inc.). On this basis the emission 
indexes were determined (related to individual exhaust components) that can be calculated as:

- instantaneous values - characterized by a great deal of fluctuation as they are calculated in each second of the test,

- values incrementing while the test is being performed, calculated as on-going on-road emission of a given exhaust component (from the onset of the test until the current moment) compared to the normative value,

- values related to the whole test as a ratio of the on-road emission in an onroad test (carried out under actual traffic conditions) to the normative value. The vehicle emission index (given exhaust component) has been defined as:

$$
\mathrm{k}_{\mathrm{j}}=\frac{\mathrm{E}_{\text {real }, \mathrm{j}}}{\mathrm{E}_{\mathrm{NEDC}(\mathrm{ETC}, \mathrm{WHTC}) \mathrm{j}}}
$$

where: $\mathrm{j} \quad-$ exhaust component for which the emission index was determined,

$\mathrm{E}_{\text {real }, \mathrm{j}}-$ emission rate under actual traffic conditions $[\mathrm{g} / \mathrm{s}]$,

$\mathrm{E}_{\mathrm{NEDC}, \mathrm{j}}$ - emission rate measured in the NEDC test $[\mathrm{g} / \mathrm{s}]$ or other tests such as those for heavy-duty vehicles (ETC, WHTC).

The emission rate under actual traffic conditions can be calculated using the characteristics of the vehicle operating time distribution $u(a, v)$ and the characteristics of the emission rate for an $j$-th exhaust component $e_{j}(a, v)$ expressed in grams per second:

$$
\mathrm{E}_{\mathrm{rzecz}, \mathrm{j}}=\sum_{\mathrm{a}} \sum_{\mathrm{v}} \mathrm{u}(\mathrm{a}, \mathrm{v}) \cdot \mathrm{e}_{\mathrm{j}}(\mathrm{a}, \mathrm{v})
$$

The on-road emission index of a given exhaust component can assume values from the range $\langle 0, \infty)$. This means that if the on-road emission from a vehicle does not exceed the normative values, the index has a value less than 1 and when the normative value is exceeded the index is greater than 1 and when the actual emissions are equal to the normative one the index equals 1 [7].

The graphs in Figure 3 show the extent of changes of the emission index for which the normative limit is met for each exhaust component (dotted line). Despite high momentary variability of the emission index its 'incrementing value' is characterized as follows:

- for carbon monoxide - a very abrupt growth during engine start and then a reduction of its value; under actual operation, in a short term, a satisfactory reduction of the emission is obtained within the limits of the required standard for both the Euro 4 and Euro 5 vehicles; the index values are comparable for the tested vehicles;

- for hydrocarbons - the course of the index changes is similar to carbon monoxide, yet the Euro 4 vehicle needed a shorter distance (approximately 2 $\mathrm{km}$ ) to reach the index value below 1. For the Euro 5 vehicle this distance was approximately $10 \mathrm{~km}$; 
- for nitric oxides - no normative requirements have been met- this mainly results from the difference of the engine operation in the NEDC test and that under actual traffic conditions; for the tested vehicles the emission index value is greater than 1 .
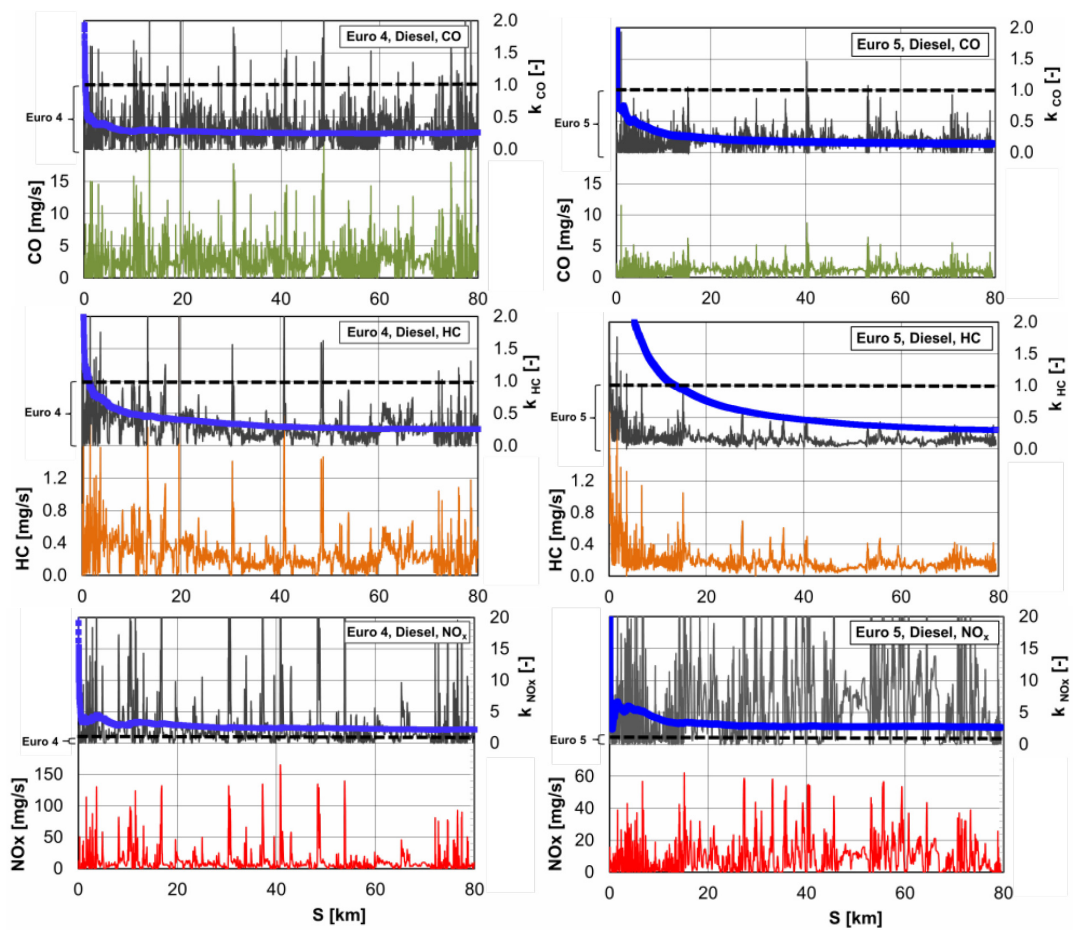

Figure 3: The values of the emission rate and indexes of on-road emission for passenger vehicles compliant with Euro 4 emission standard, and Euro 5 emission standard.

The values of the exhaust emission indexes for passenger vehicles were determined based on the performed tests under actual traffic conditions. For the determination of the emission indexes for the outstanding categories the authors adopted the results of earlier works carried out by the research team with the Chair of Combustion Engines at Poznan University of Technology [4-6]. For the category of low emission vehicles the emission indexes assume values much greater than 1 in the initial driving phases but then they decrease to a value of several per cent of the value set forth in the emission standard (this dependence is the case for the emission of carbon monoxide and hydrocarbons). Contrary to the presented scheme is the course of the emission index for nitric oxides: it decreases its value, but it does not reach the level set forth in the emission standard. For this reason under actual traffic conditions the emission of nitric oxides is several times above the admissible limit - this dependence was 


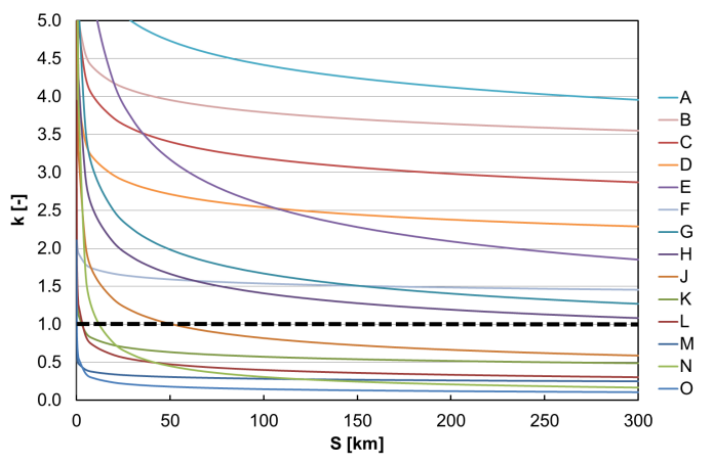

Figure 4: Curves of the exhaust emission indexes.

confirmed in the tests of heavy-duty vehicles and city buses. For the rest of the vehicles of different emission categories the emission index curves $k=f(S)$ were determined as dependent on the distance covered by the vehicles (Fig. 4, Tab. 1).

Table 1: Courses of the exhaust emission index curves assigned to individual vehicle types and corresponding emission categories.

\begin{tabular}{|c|c|c|c|c|c|c|c|c|c|c|}
\hline \multirow{2}{*}{ Vehicle } & \multirow{2}{*}{ Engine } & & \multicolumn{8}{|c|}{ Exhaust emission index } \\
\hline & & & E0 & E1 & E2 & E3 & E4 & E5 & E6 & E7 \\
\hline \multirow{6}{*}{$\mathrm{PC}$} & \multirow{3}{*}{ Petrol } & $\mathrm{CO}$ & $\mathrm{A}$ & $\mathrm{B}$ & $\mathrm{H}$ & $\mathrm{J}$ & $\mathrm{O}$ & $\mathrm{O}$ & $\mathrm{O}$ & $\mathrm{O}$ \\
\hline & & $\mathrm{HC}$ & $\mathrm{A}$ & B & $\mathrm{H}$ & $\mathrm{J}$ & $\mathrm{O}$ & $\mathrm{O}$ & $\mathrm{O}$ & $\mathrm{O}$ \\
\hline & & $\mathrm{NO}_{\mathrm{x}}$ & $\mathrm{A}$ & $\mathrm{D}$ & $\mathrm{G}$ & $\mathrm{J}$ & $\mathrm{M}$ & $\mathrm{N}$ & $\mathrm{N}$ & $\mathrm{N}$ \\
\hline & \multirow{3}{*}{ Diesel } & $\mathrm{CO}$ & $\mathrm{A}$ & $\mathrm{D}$ & $\mathrm{H}$ & $\mathrm{J}$ & $\mathrm{L}$ & $M$ & $\mathrm{O}$ & $\mathrm{O}$ \\
\hline & & $\mathrm{HC}$ & $\mathrm{A}$ & $\mathrm{D}$ & $\mathrm{H}$ & $\mathrm{J}$ & $\mathrm{N}$ & M & $\mathrm{O}$ & $\mathrm{O}$ \\
\hline & & $\mathrm{NO}_{\mathrm{x}}$ & $\mathrm{A}$ & $\mathrm{F}$ & $\mathrm{G}$ & $\mathrm{E}$ & $\mathrm{J}$ & $\mathrm{C}$ & B & $\mathrm{D}$ \\
\hline \multirow{6}{*}{ LCV } & \multirow{3}{*}{ Petrol } & $\mathrm{CO}$ & $\mathrm{B}$ & $\mathrm{C}$ & $\mathrm{E}$ & $\mathrm{G}$ & $M$ & $\mathrm{~N}$ & $\mathrm{O}$ & $\mathrm{O}$ \\
\hline & & $\mathrm{HC}$ & $\mathrm{B}$ & $\mathrm{C}$ & $\mathrm{E}$ & $\mathrm{E}$ & M & $\mathrm{N}$ & $\mathrm{O}$ & $\mathrm{O}$ \\
\hline & & $\mathrm{NO}_{\mathrm{x}}$ & $\mathrm{E}$ & $\mathrm{G}$ & $\mathrm{G}$ & $\mathrm{J}$ & $\mathrm{K}$ & $\mathrm{K}$ & $\mathrm{L}$ & $\mathrm{L}$ \\
\hline & \multirow{3}{*}{ Diesel } & $\mathrm{CO}$ & $\mathrm{F}$ & $\mathrm{H}$ & $\mathrm{J}$ & $\mathrm{K}$ & $\mathrm{L}$ & $\mathrm{N}$ & $\mathrm{O}$ & $\mathrm{O}$ \\
\hline & & $\mathrm{HC}$ & $\mathrm{F}$ & $\mathrm{H}$ & $\mathrm{J}$ & $\mathrm{K}$ & $\mathrm{L}$ & $\mathrm{N}$ & $\mathrm{O}$ & $\mathrm{O}$ \\
\hline & & $\mathrm{NO}_{\mathrm{x}}$ & $\mathrm{J}$ & $\mathrm{H}$ & $\mathrm{G}$ & $E$ & $\mathrm{D}$ & $\mathrm{C}$ & $\mathrm{B}$ & $\mathrm{D}$ \\
\hline \multirow{3}{*}{ HDV } & \multirow{3}{*}{ Diesel } & $\mathrm{CO}$ & $\mathrm{A}$ & C & $\mathrm{J}$ & $\mathrm{K}$ & $\mathrm{L}$ & $\mathrm{N}$ & $\mathrm{O}$ & $\mathrm{O}$ \\
\hline & & $\mathrm{HC}$ & $\mathrm{B}$ & $\mathrm{C}$ & $\mathrm{J}$ & $\mathrm{K}$ & $\mathrm{L}$ & $\mathrm{N}$ & $\mathrm{O}$ & $\mathrm{O}$ \\
\hline & & $\mathrm{NO}_{\mathrm{x}}$ & $\mathrm{F}$ & $E$ & $\mathrm{E}$ & E & $\mathrm{D}$ & $\mathrm{B}$ & $\mathrm{B}$ & $\mathrm{D}$ \\
\hline \multirow{3}{*}{ Bus } & \multirow{3}{*}{ Diesel } & $\mathrm{CO}$ & $\mathrm{A}$ & B & $\mathrm{D}$ & $\mathrm{K}$ & $\mathrm{L}$ & $\mathrm{M}$ & $\mathrm{O}$ & $\mathrm{O}$ \\
\hline & & $\mathrm{HC}$ & $\mathrm{B}$ & B & $\mathrm{D}$ & $\mathrm{K}$ & $\mathrm{L}$ & $M$ & $\mathrm{O}$ & $\mathrm{O}$ \\
\hline & & $\mathrm{NO}_{\mathrm{x}}$ & $\mathrm{F}$ & $E$ & $\mathrm{C}$ & $\mathrm{E}$ & $\mathrm{D}$ & $\mathrm{B}$ & $\mathrm{B}$ & $\mathrm{D}$ \\
\hline \multirow{3}{*}{ Motorcycle } & \multirow{3}{*}{ Petrol } & $\mathrm{CO}$ & $\mathrm{A}$ & $\mathrm{A}$ & $\mathrm{H}$ & $\mathrm{J}$ & $\mathrm{O}$ & $\mathrm{O}$ & $\mathrm{O}$ & $\mathrm{O}$ \\
\hline & & $\mathrm{HC}$ & $\mathrm{A}$ & $\mathrm{A}$ & $\mathrm{H}$ & $\mathrm{J}$ & $\mathrm{O}$ & $\mathrm{O}$ & $\mathrm{O}$ & $\mathrm{O}$ \\
\hline & & $\mathrm{NO}_{\mathrm{x}}$ & $\mathrm{E}$ & $\mathrm{G}$ & $\mathrm{G}$ & $\mathrm{J}$ & $\mathrm{N}$ & $\mathrm{N}$ & $\mathrm{N}$ & $\mathrm{N}$ \\
\hline
\end{tabular}

\section{Modeling of the exhaust emissions for the Poznan agglomeration}

Based on the prepared data, daily exhaust emissions from vehicles were determined in the Poznan agglomeration assuming that the emissions from vehicles are dependent on the distance covered by the vehicles and changes 
according to the curve of the changes in the emission index (case I) or that the emissions from the vehicles reach a value set forth in the emission standard and is independent of the distance covered by the vehicles (case II). These values were calculated for each vehicle group categorized into type of power train and exhaust emission component (Fig. 5). The comparison was made for the Poznan agglomeration referred to the years 2012-2030; from the analysis of this period it results that the overall emission level is decreasing, yet it shows a significant growth in the emission from heavy-duty vehicles (this is a result of including the bypass section of the A2 expressway in the calculations).
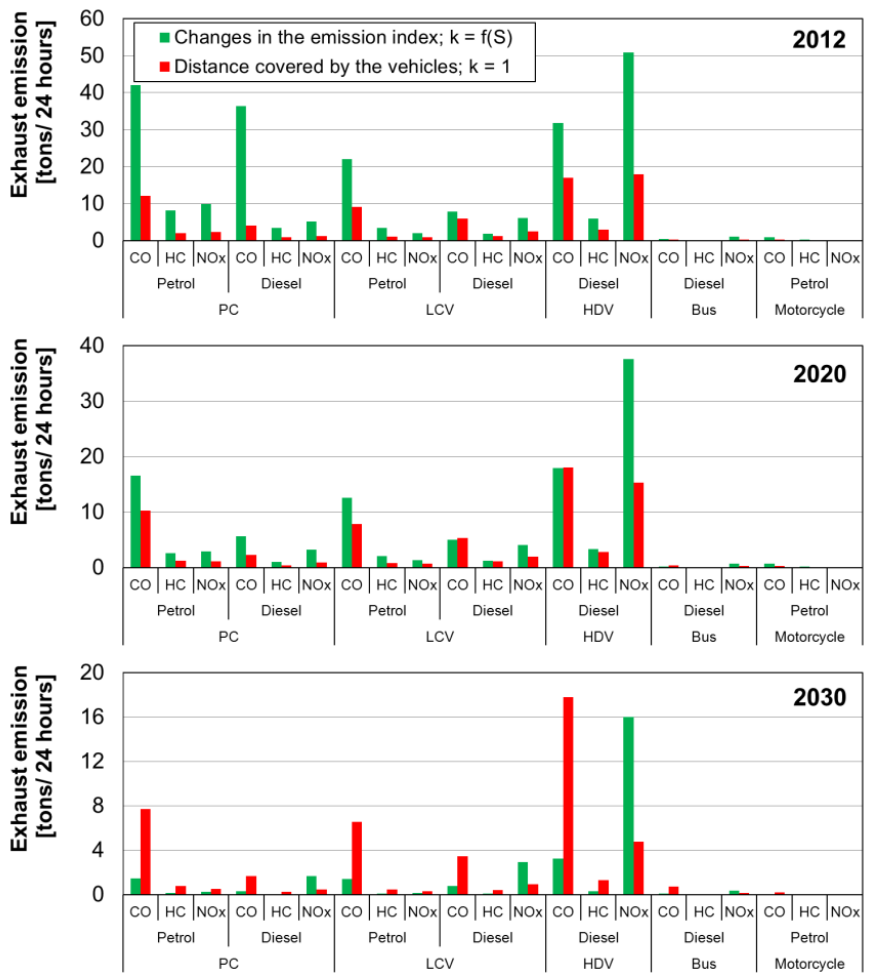

Figure 5: The emission level for the vehicles in the years 2012-2030 for two methods of determining the exhaust emissions from a single vehicle.

When modeling the exhaust emissions the authors minded the vehicle category that is the most harmful for the environment. The results of the analysis show the greatest share of the exhaust emissions from the oldest vehicles even though they were only $16 \%$ in 2012 and in their share in 2020 is forecasted on the level of $4 \%$. The growing number of vehicles of more environment friendly emission categories does not result in a substantial growth of the global exhaust emissions - the oldest vehicles (uncontrolled exhaust emissions) have the 
greatest share in the exhaust emissions. This situation changes only after 2030, when it is assumed that the oldest vehicles would be very small in number. The method of pollution calculations is noteworthy as well: for the years 2012 and 2020 the obtained values of the exhaust emissions are greater (most conspicuous for the oldest vehicles) when we assume the fulfillment of a standard dependent on the covered distance. This means that vehicles of low emission categories generate much more pollution than it results from the emission standard met by these vehicles (Fig. 6).
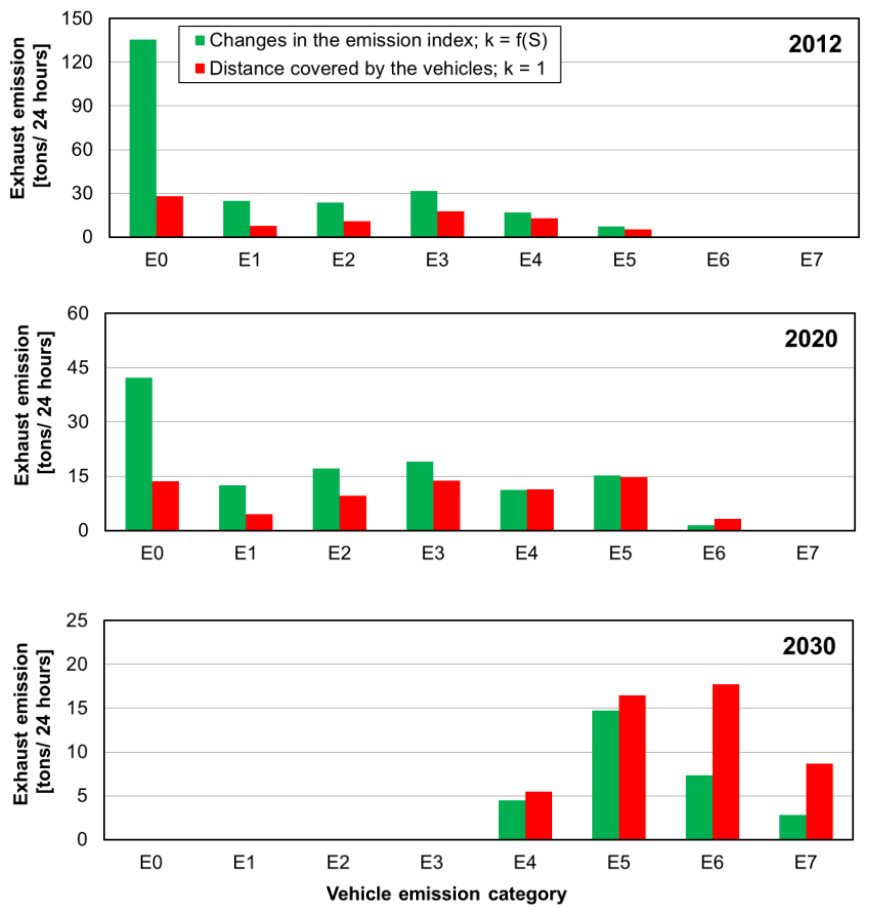

Figure 6: The exhaust emissions for the Poznan agglomeration (dividing vehicles into emission categories).

Determining the exhaust emissions for subsequent years we obtain a value that can be compared with values assumed for individual vehicles. If we assume the normative values for the emission modeling then for the year 2012 we obtain underestimated values by approximately $60 \%$; for the year 2020 these values will be underestimated by approximately $40 \%$ and for the year 2030 the obtained values will be overestimated by approximately $40 \%$. Hence, we should aim at a precise determination of the input quantities for the modeling of the exhaust emissions, which can be obtained through vehicle tests under actual traffic conditions (Fig. 7). 


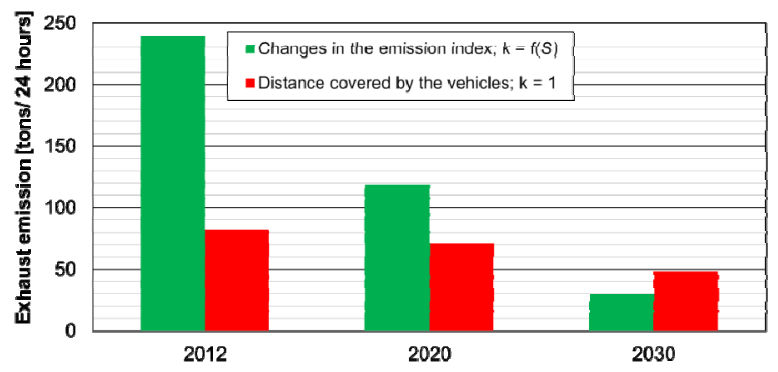

Figure 7: The comparison of the exhaust emission values for the assumed modeling years depending on the method of determination of the exhaust emissions from an individual vehicle.

A varied approach to the estimation of the emissions from individual vehicles and its introduction to the models of global emissions is reflected in the results presenting the shares of the exhaust emissions in individual years from different types of vehicles. When analyzing the emission of carbon monoxide, in the emission of which the greatest share (approximately 55\%) have passenger vehicles in the year 2012, we can observe that this share decreases in the successive years (in the year 2020 and 2030 to 38\% and 24\% respectively (Fig. 8).
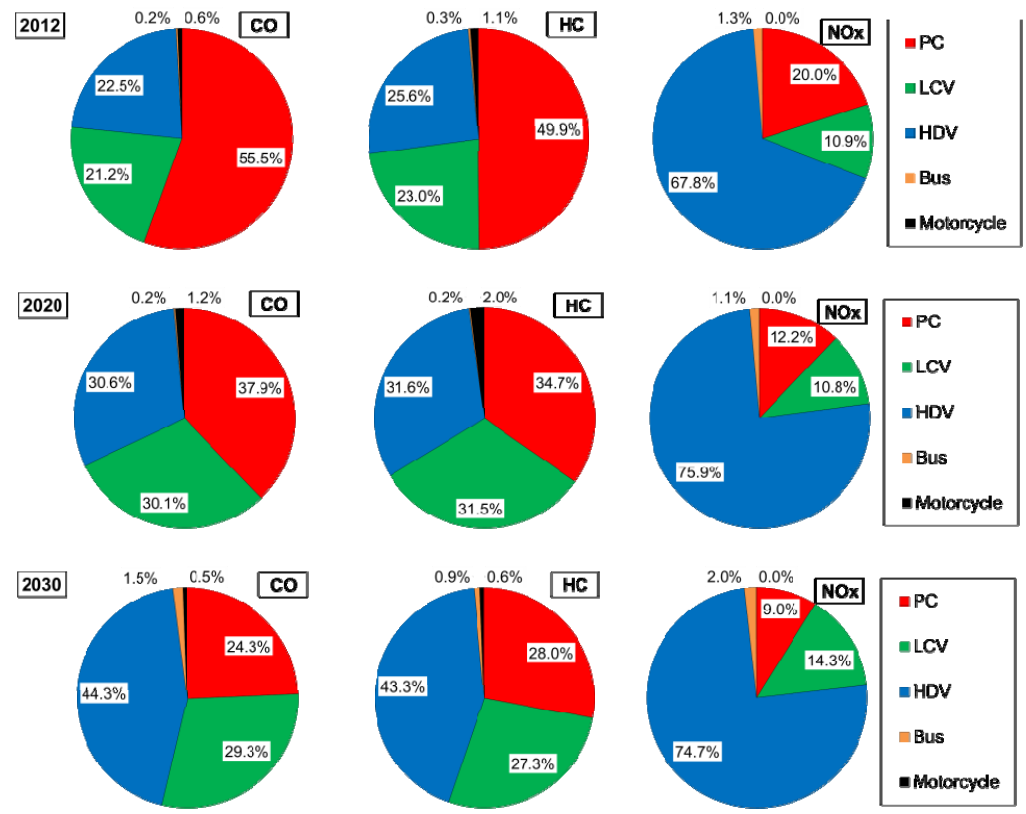

Figure 8: The share of different vehicle categories in the total emission of a given exhaust component assuming the dependence of the emission on the distance covered $(k=f(S))$. 
The greatest share in the emission of hydrocarbons also have passenger vehicles in the year 2012 and similarly to the share of the emission of carbon monoxide it will gradually decrease in the coming years. Yet, a disturbing phenomenon will be the increase in the share of the emission of carbon monoxide and hydrocarbons from heavy-duty vehicles in the successive years (2012, 2020 and 2030 , to $26 \%, 32 \%$ and $44 \%$ respectively). The values, however, do not confirm the increasing emission of these components but only point to a change in the structure of vehicles for which the emissions are monitored.

The values are different if we assume the value of the normative limit for a given exhaust component as the basis for the determination of the emissions from an individual vehicle (Fig. 9). If the emission indexes assumed constant values, independent from the distance covered by the vehicles, the share of the emissions from Fig. 8 and Fig. 9 would be identical. Yet, the adoption of variable emission indexes (that more accurately reflect the actual values of the emissions generated by vehicles) boosts the reliability of the emission modeling.
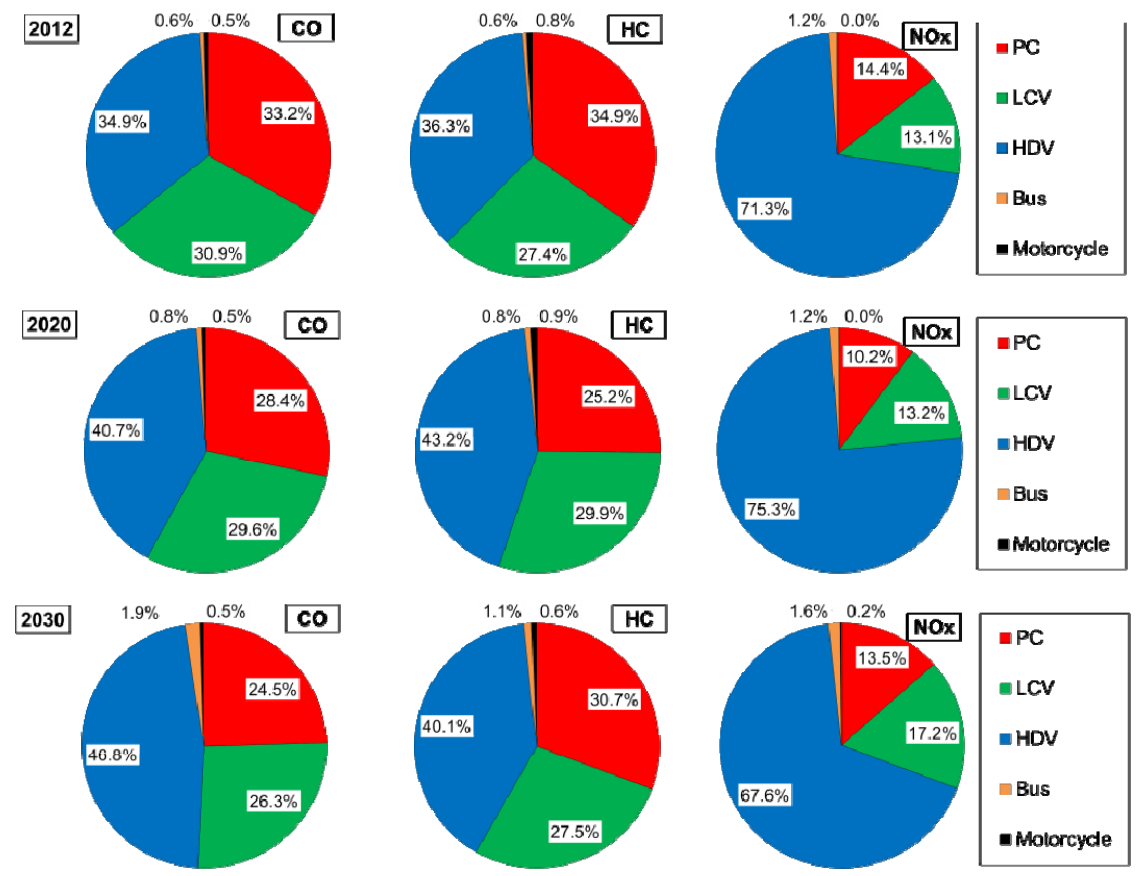

Figure 9: The share of different vehicle categories in the total emissions of a given exhaust component assuming the independence of the exhaust emissions from the distance covered by the vehicle $(\mathrm{k}=1)$. 
It is noteworthy that, irrespective of the method of assumption of the values of the emissions for individual vehicles, heavy duty vehicles have the greatest share in the emission of nitric oxides, almost irrespective of the year for which this value was estimated.

\section{Conclusions}

In the paper the authors presented the results of the modeling of the exhaust emissions from road transport in the Poznan agglomeration. The values of the exhaust emissions were estimated assuming that the most reliable input parameters are the values of the exhaust emissions from individual vehicles determined under actual traffic conditions. The values of the exhaust emissions were determined using portable analyzers and, then, these values were compared to the normative values. On this basis the emission indexes were determined depending on the distance covered by the vehicles $(k=f(S))$. It has been confirmed that such a procedure described the global emissions in a more reliable way than it is in the case of assuming model input values corresponding to those set forth in the emission standards (the model input value of the exhaust emissions from a vehicle equals the emission limit set for a given vehicle emission category, $\mathrm{k}=1$ ). It has been proven that when determining the exhaust emissions for the year 2012 the greatest impact on these emissions have the oldest vehicles (whose share is approximately 16\%) and at the same time the assumption of an index independent from the distance covered by vehicles results in an underestimation of the exhaust emissions by approximately $60 \%$.

\section{References}

[1] Bonnel, P., Weiss and M., Provenza, A., In-use Emissions Requirements in the New and Future European Motor Vehicle Emissions Regulations: State of Play. 8th Annual SUN Conference, Ann Arbor 2011.

[2] Bougher, T., Khalek, I.A., Trevitz, S. and Akard, M., Verification of a Gaseous Portable Emissions Measurement System with a Laboratory System Using the Code of Federal Regulations Part 1065. SAE Technical Paper Series 2010-01-1069, 2010.

[3] Chłopek, Z., Some remarks on engine testing in dynamic states. Combustion Engines, No. 4, 2010.

[4] Merkisz, J., Pielecha, I. and Pielecha, J., Gaseous and PM Emission from Combat Vehicle Engines during Start and Warm-Up. SAE Technical Paper Series 2010-01-2283, 2010.

[5] Merkisz, J. and Pielecha, J., Exhaust Emissions during Cold Start Gasoline and Diesel Engine from Passenger Cars. Combustion Engines, No. 3, 2011.

[6] Merkisz, J. and Pielecha, J., The On-Road Exhaust Emissions Characteristics of SUV Vehicles Fitted with Diesel Engines. Combustion Engines, No. 2, 2011. 
[7] Merkisz, J., Pielecha, J. and Radzimirski, S., Emisja zanieczyszczeń motoryzacyjnych w świetle nowych przepisów Unii Europejskiej. WKŁ, Warszawa 2012.

[8] Ortenzi, F. and Costagliola, M.A., A New Method to Calculate Instantaneous Vehicle Emissions using OBD Data. SAE Technical Paper Series 2010-01-1289, 2010.

[9] Regulations Commission: Regulation No 582/2011 of 25 May 2011 implementing and amending Regulation No 595/2009 of the European Parliament and of the Council with respect to emissions from heavy duty vehicles (Euro VI) and amending Annexes I and III to Directive 2007/46/EC of the European Parliament and of the Council, 2011.

[10] Schöppe, D., Greff, A., Zhang, H., Frenzel, H., Rösel, G., Achleitner, E. and Kapphan, F., Requirements for Future Gasoline DI Systems and Respective Platform Solutions. 32th Internationales Wiener Motorensymposium 2011, Vienna 2011.

[11] Sommer, K., Continental Mobility Study 2011, Hanover 2011 (www.contionline.com).

[12] www.emisia.com. 